\title{
Ply fragmentation in unidirectional hybrid composites linked to stochastic fibre behaviour: a dual-scale model
}

\author{
Francisco Mesquita*, Yentl Swolfs, Stepan V. Lomov, Larissa Gorbatikh \\ Department of Materials Engineering, KU Leuven \\ Kasteelpark Arenberg 44 box 2450, 3001 Leuven, Belgium \\ *Corresponding author: francisco.mesquita@kuleuven.be, +3216373686
}

\begin{abstract}
Ply fragmentation is a dual-scale phenomenon comprised of fibre breaks at the microlevel and ply fractures at the meso-level. A dual-scale stochastic model is proposed to predict the longitudinal tensile behaviour of unidirectional interply fibre-hybrid composites, including ply fragmentation in low elongation (LE) plies. The predictions of the stress-strain diagram are validated for carbon/glass hybrid composites and agree well with experimental results. A parametric study was performed where the Weibull scale parameter of the high elongation (HE) fibres and shape parameter of the LE fibres were varied. The Weibull scale parameter of the HE fibres strongly influences the failure mode of the hybrid composite. An LE fibre type with a low Weibull modulus should be used if a composite with a smooth stress-strain diagram is desirable. The model presented can be used for any layup and material configuration, contributing to a more intelligent and efficient design of hybrid composites.
\end{abstract}

Keywords: Hybrid composites (A); fragmentation (B); mechanical properties (B); modelling $(\mathrm{C})$

\section{Introduction}

Fibre-hybrid composites contain at least two fibre types within one matrix. The two fibre types are typically referred to as low elongation (LE) and high elongation (HE) fibres [1]. Hybridisation has the advantage of balancing the properties of both fibre types. For example, the hybrid composite stiffness is increased relative to the more compliant fibre type composite. The toughness of the LE fibre composite can also be increased through hybridisation. Fibre-hybrids can be designed with three types of microstructure: interply, intraply and intrayarn. Interply hybrids consist of a stack of plies of different fibre types. Their manufacture is easier compared to intraply and intrayarn hybrids.

Unidirectional (UD) interply hybrids can fail in a gradual manner under longitudinal tensile load. The LE plies fracture before the HE plies. With the right proportions of the each fibre type, the HE plies can survive the increased load shed by the LE plies. Using thin LE plies, pseudo-ductile behaviour can be achieved [2], enabling a damaged part to continue to remain functional after the failure of the LE plies. If the delamination occurring upon an LE ply fracture is small and the LE ply is able to carry loads due to 
the shear stress transfer from the adjacent intact HE plies, then multiple fractures can happen in the LE ply, a phenomenon known as ply fragmentation.

Each ply fracture is triggered by accumulation of fibre breaks. Several models for longitudinal tensile strength are based on the accumulation of fibre breaks in a UD fibre-hybrid composite [3-7]. These models describe the phenomena at the micro-level for intrayarn hybrids but neglect the laminated structure of the composite and thus miss the inherent failure mechanisms on the ply level. Other modelling approaches consider the stacked nature of interply fibre-hybrids but ignore the fibre break accumulation [811]. Currently there are no models that consider both the micro- and meso-level failure phenomena in UD hybrid composites. The micro-level events are related to fibre breakage while the meso-level events are ply fractures. Synergies found in hybrid composites are typically a result from complex interactions $[1,12]$. Models that consider both levels are needed if one wants to fully exploit those synergies.

The present work fills this gap and proposes a dual-scale approach to predict the tensile behaviour of fibre-hybrid composites failing by ply fragmentation. The main characteristics predicted by the model are the stress-strain diagram, the failure strain distribution, the ply fragment length and the fibre break development. The modelling approach is first validated against experimental results for carbon/glass hybrids and then used to evaluate the tensile behaviour of interply fibre-hybrids with prevailing LE ply fragmentation failure mode.

\section{Modelling approach}

Consider a UD fibre-hybrid composite with $\mathrm{N}$ plies where each LE ply is stacked between HE plies (see Figure 1). The LE plies are thin and HE plies are thick. The fibre positions on the ply cross-section are created using a random fibre packing generator developed by Melro et al. [13-15]. The generator was modified to take into account laminated structure of the hybrid composite and calculates the positioning of the LE and HE fibres in their respective plies. Each fibre position is generated randomly but the fibre type is decided according to the position of the fibre in the thickness direction. The fibres are assumed to be parallel one to another, hence their locations in the crosssection fully defines geometry of the problem. The boundary between plies is defined using Voronoi tessellation [16]. The polygon lines separating fibres belonging to different plies are connected and form the ply interface.

The composite is loaded in tension along the fibre direction, increasing the global strain incrementally. The strain increment depends on the number of fibres broken, being shorter as the number of fibre breaks increases. Each fibre is divided into elements along its length, where each element is $7 \mu \mathrm{m}$ long, and the stress in each fibre element is compared to its strength, which was randomly assigned (see Section 2.1). In a given element, if the longitudinal stress is higher than the strength, a new fibre break occurs. The current version of the model does not account for the effect of multi-axial stresses on fibre breakage. The presence of the fibre break changes the local stress field as the broken fibre loses its load carrying capacity and sheds the load to nearby fibres [15]. The nearby fibre elements are therefore more likely to break, creating a tendency to 
form fibre break clusters. When a cluster becomes unstable, the number of fibre breaks in the respective ply increases rapidly and results in a ply fracture.

A ply fracture is defined in the location where the unstable cluster occurred.

Delamination is suppressed in thin LE ply hybrid composites [17] and therefore perfect bonding between the layers is assumed in the fibre break model. The broken ply carries no load at the fracture location but recovers its load carrying capacity at a certain distance from the ply fracture [18]. The stress recovery in the broken ply and consequent stress increase in the other plies is obtained through finite element (FE) modelling. The presence of the ply fracture results in a different stress-strain response in comparison with the undamaged material. The new apparent stiffness is the response of the material in the presence of damage. Through an equivalence of the FE model, the apparent stiffness of a damaged composite can be calculated (see below).

With the development of fibre breaks, new ply fractures can occur in the same ply, a phenomenon known as ply fragmentation. The stress redistribution near a ply fracture depends on the distance between the fracture and the closest fracture in the same ply. The composite is considered to have failed if all the plies contain at least one ply fracture.

The next sections describe the details of the modelling approach, such as the FE model used to determine the stress redistribution near ply fractures or the transition between the micro- and meso-levels. Figure 2 represents the flow chart of the model and gives an overview of the modelling approach.

\subsection{Ply stress redistribution (meso-level)}

Upon ply fracture, there is a stress re-distribution in its vicinity. To capture the stress redistribution and stiffness degradation around a ply fracture, an FE model is created using ABAQUS 2017 (see Figure 3a). The Cartesian coordinate system is aligned with the width (X), thickness (Y) and length $(\mathrm{Z})$ directions of the ply. The face $Z=0$ represents the ply fracture plane.

The FE model is created with the detailed geometry of the fibres and matrix to account for the plasticity in the matrix $[19,20]$, as the homogenisation of the ply would hinder this effect. The packing at the width (X) boundaries satisfies periodicity. The potential crack surface in the ply boundary is created using Voronoi tessellation as described in section 2 .

Two types of conditions are applied in the fracture surface plane $Z=0$. Symmetry boundary conditions are applied to the intact ply's fibres and matrix while the broken plies remain traction-free. On the opposite face, a uniform displacement of magnitude $\bar{\varepsilon} \times L_{\text {model }}$ is applied, where $\bar{\varepsilon}$ is the global strain and $L_{\text {model }}$ is the length of the model. The nodes in the faces parallel to the $\mathrm{YZ}$ plane with the same $\mathrm{Y}$ and $\mathrm{Z}$ coordinates but in opposite faces are tied in such a way that their displacement is equal. This boundary condition implies a periodicity in the width direction, justified by the large width used in the fibre break model in comparison with the FE model. The edge effects in the fibre break model are taken into account by using an enhanced linear superposition (see 
Section 2.2). The model's dimensions are $100(\mathrm{X}) \mathrm{x}$ thickness (Y) x $2085(\mathrm{Z}) \mu \mathrm{m}^{3}$, where the thickness $(Y)$ dimension was varied. Averaging the stress over all finite elements in the cross-section of a fibre, the stress in a fibre depends only on the distance to the ply fracture surface. The FE model's length was chosen is such a way that the stress in the fibres varied less than $0.1 \mathrm{MPa} / \mu \mathrm{m}$ between the last two positions farthest away from the ply fracture in the longitudinal direction (see Figure $3 \mathrm{c}$ ).

Once an FE solution under certain applied strain $\bar{\varepsilon}$ is obtained, the stress field for any given strain level can be calculated by determining the stress concentration factor (SCF) over the fibre cross-section. The $S C F$ s are given by equation 1 :

$\operatorname{SCF}(i, z)=\frac{\sigma(i, z)-\sigma_{\text {far field }}(i)}{\sigma_{\text {far field }}(i)}$

where the $\operatorname{SCF}(i, z)$ is the SCF in the fibre $i$ averaged in all the finite elements at the same distance $z$ from the ply fracture surface, and $\sigma(i, z)$ is the average stress in all finite elements in the cross-section of the fibre $i$ with coordinate $z$. The far field stress corresponds to the cross-section farthest away from the ply fracture plane (see Figure 3).

Each fibre $i$ is located at a certain distance $d$ from the nearest broken ply boundary. The distance $d$ is determined between the surface of the fibre and the nearest point in the boundary of the broken ply. Knowing the distance $d$ for all fibres in the FE model, a "master" function $S C F(d, z)$ is built. The "master" function is discrete and known exactly only for the distances of the fibres present in the FE model packing. The data points in the "master" function correspond to the FE model results. In the fibre break model [6,21-23] more fibres are used and therefore there is a need to know the value of this function continuously for all distances from the broken ply boundary. An approximation by a second degree polynomial surface $\Phi(\mathrm{d}, \mathrm{z})$ is made to $S C F(d, z)$ using MATLAB 2018a. The FE model predictions and corresponding surface fit are shown in Figure 3c.

The stress-strain response of the composite with a ply fracture is different than the response of an undamaged composite. The new apparent stiffness leads to a lower far field stress in all fibres than expected for the applied displacement. An equivalence is made between the composite with the ply fracture and an undamaged composite with the same apparent stiffness. The apparent stiffness of the equivalent undamaged composite can be determined from the results of the FE model. The equivalent apparent stiffness is determined using equation 2 :

$E_{a}^{\prime}=\frac{\sum_{j=1}^{n_{\text {fibres }}} \sigma_{j, \text { far field }} \cdot A_{j}}{\bar{\varepsilon} \cdot \sum_{j=1}^{n_{\text {fibres }}} A_{j}}$

where $n_{\text {fibres }}$ the number of fibres in the FE model, $\sigma_{j, \text { far field }}$ the far field stress in the fibre $j$, obtained as in equation $1, A_{j}$ the cross-sectional area of the fibre $j$ and $\bar{\varepsilon}$ is the global strain used to determine the applied displacement. 
The fibre break model's length is higher than the FE model's length. To capture the effect of the reduction of the apparent stiffness due to the presence of damage, the fibres in the damaged ply are considered to have a variable stiffness. An equivalent composite with the same apparent stiffness can be created, where the composite's apparent stiffness is the weighted average of the stiffness of the intact and damaged fibres. The equivalent apparent stiffness can therefore be determined using equation 3 :

$E_{a}^{\prime}=v_{f_{i}} \cdot \bar{E}_{i}+v_{f_{b}} \cdot E_{b}^{\prime}$

where $v_{f_{i}}$ and $v_{f_{b}}$ the fibre volume fraction in the intact and broken plies, respectively, $\bar{E}_{i}$ the average stiffness of the intact fibres, weighed by the total area of each fibre type and $E_{b}^{\prime}$ is the apparent stiffness of the broken fibres. For each broken fibre, the stiffness is set equal to the nominal stiffness for $z$ greater than a stiffness recovery length, $L_{r e c}$, but varies linearly between zero and the nominal stiffness for $z$ lower than $L_{r e c} / 2$ (see Figure 3d). Given the stiffness variation in the broken fibres and re-working equation 3 , $L_{r e c}$ can be obtained using equation 4 :

$L_{\text {rec }}=4 \cdot L_{\text {model }} \cdot\left[1-\left(E_{a}^{\prime}-v_{f_{i}} \cdot \bar{E}_{i}\right) /\left(v_{f_{b}} \cdot E_{b}\right)\right]$

where $L_{\text {model }}$ is the model length and $E_{b}$ is the nominal stiffness of the broken fibres. FE models with four different model lengths $(635,805,1020$ and $2085 \mu \mathrm{m})$ were used to determined $L_{r e c}$ and no influence was found on the value of $L_{r e c}$, hence validating the approach. The stiffness recovery length is therefore independent of the model length due to the relationship between $L_{\text {model }}$ and $E_{a}^{\prime}$.

The model also takes into account the interaction between ply fractures in the same ply. The FE model described for one LE ply is therefore modified (see Figure $3 b$ ). The model length (along Z-coordinate) is increased by half of the distance between ply fractures $d l \_$fract and symmetry boundary conditions are applied to the face $Z=0$. The second LE ply fracture is represented by a "seam crack" at $z=d l \_$fract. The seam crack duplicates the nodes in the broken ply surface, allowing them to be separated, thus creating a crack. All the other features of the FE model remain as described before. The SCF field near the ply fractures and apparent stiffness reduction is controlled by the opening displacement of the fractured surface. The presence of the interacting ply fracture changes the fracture surface displacement, having an influence on the SCF field and apparent stiffness degradation. The FE model with interactions is executed for distances between the ply fractures ranging from 0.5 to 2.5 times the ply's ineffective length. The ply ineffective length is twice the distance between the ply fracture location and the location where the ply has recovered $90 \%$ of the nominal stress [24].

The effect of the interactions between ply fractures on the stiffness degradation is taken into account assuming that $L_{r e c}$ in the (+) side of the ply fracture (see Figure $3 b$ ) is equal to the case where no interaction is considered (see Figure $3 a) . L_{r e c}^{\prime}$, in the (-) side of the ply fracture is therefore given by equation 5:

$L_{\text {rec }}^{\prime}=4 \cdot\left[\left(L_{\text {model }}+0.5 \cdot L_{r e c}\right)-\left(E_{a}^{\prime}-v_{f_{i}} \cdot E_{i}\right) \cdot \frac{L_{\text {model }}}{v_{f_{b}} \cdot E_{b}}\right]$ 
The ply fractures occur stochastically in the dual-scale model (see a detailed explanation in Section 2.3). As they occur, $\Phi(d, z)$ is applied according to the distance between two consecutive fractures. $L_{r e c}$ also depends on the distance between fractures and is linearly interpolated between the FE model results. Each fibre element has an apparent stiffness value that is modified depending on the distance, $z$, to the nearest ply fracture. In the dual-scale model, the apparent stiffness, $E_{A}(z)$, is given by equation 6 :

$E_{A}(z)=\frac{z}{L_{r e c}} \times E_{\text {nominal }} \quad$ for $z<L_{r e c} / 2$

Where $z$ is the distance to the ply fracture and $E_{\text {nominal }}$ is the fibre's nominal stiffness. The maximum distance for which the ply fractures interact is obtained from the FE model results by comparing the distance $L_{r e c}$ in the FE model with and without interactions. If the difference between $L_{r e c}$ and $L_{r e c}^{\prime}$ is less than $1 \%$, the ply fractures are assumed to be sufficiently far apart and do not interact. In that case, the reference $\Phi(d, z)$ and $L_{r e c}$ for a single ply fracture are applied.

\subsection{Fibre failure mechanisms (micro-level)}

The modelling approach at the micro-level has been extensively described in literature [6,21-23]. The parallel fibres are divided along their length into elements with equal lengths $L$. Each element is assigned a strength value according to a unimodal Weibull probability distribution (see equation 7 ):

$P=1-\exp \left[-\left(\frac{L}{L_{0}}\right) \cdot\left(\frac{\sigma_{f}}{\sigma_{0}}\right)^{m}\right]$

where $P$ is the probability that a fibre element with a length $L$ fails when an axial stress $\sigma_{f}$ is applied to it, $L_{0}$ is the reference gauge length, $\sigma_{0}$ is the Weibull strength scale parameter and $m$ is the Weibull modulus. The use of a unimodal Weibull distribution may lead to large errors when extrapolated to short gauge lengths. More detailed descriptions exist for carbon fibres where bimodal distributions are used [25-30]. Nevertheless, this description type was not available for the carbon fibre type used in this work and a unimodal Weibull distribution was therefore assumed. A fibre element breaks if the stress applied to it is higher than the element's stochastic strength.

The stress fields in the vicinity of fibre breaks are based on results from an FE model that calculates the stress redistribution near single fibre breaks $[15,18,19]$. The FE model consists of a broken LE or HE fibre surrounded by a random packing of LE and HE intact fibres. The total fibre volume fraction in the packing was $50 \%$ and the relative volume fraction of LE and HE fibres was also $50 \%$. Using an intrayarn packing to describe the stress redistribution near fibre breaks in an interply hybrid is an imperfect solution. Nevertheless, previous results proved that the SCF field in hybrid packings is primarily affected by the broken fibre type, but hardly affected by the LE fibre volume fraction [15]. The use of an intrayarn packing reduces the complexity of the model, as compared to having a combination of hybrid and non-hybrid packings to calculate the stress redistributions. If multiple fibre breaks occur near each other, then stress concentrations on the nearby intact fibres are the result of the combination of the SCFs due to the individual fibre breaks. The total SCF in those intact fibres is then calculated 
using an enhanced linear superposition, which is explained and validated in more detail elsewhere [23].

One new development relative to the base model is the inclusion of the apparent stiffness modification as described in section 2.1. Considering only one fibre to be broken and the remaining intact, equation 4 can still be used to determined $L_{r e c}$. In this case, $\bar{E}_{\iota}$ and $v_{f_{i}}$ are the average nominal stiffness and fibre volume fraction of LE and HE intact fibres and not the nominal stiffness of the fibre type in the intact ply.

As fibre breakages occur in the dual-scale model, the stress re-distribution increases the chances of fibre elements nearby the fibre break to fail. The fibre breaks therefore tend to form clusters. Fibre break clusters are defined by the interaction between two fibres. When a fibre breaks, it sheds the load it was carrying to the nearest fibres, increasing their stress and failure probability. If one of the nearest fibres fails due to a stress concentration higher than $1 \%$, the two fibres are considered to be part of the same cluster.

\subsection{From fibre breaks to ply fractures}

When a fibre break cluster grows unstably, a ply fracture occurs. The transition from the micro to the meso-level occurs when unstable cluster growth is detected. Calculating the development of that unstable cluster into a complete ply fracture is computationally demanding. A failure criterion is therefore used for the early detection of a ply fracture.

The unstable growth of a cluster can be detected numerically by a rapid increase in the number of fibre breaks within a narrow section in the axial direction. In the fibre break model, as the strain is incremented, new fibre breaks are detected. As fibre elements may fail due to the stress changes, new broken fibres are iteratively searched for within the same strain increment. If the number of new fibre breaks increases for 4 consecutive iterations, a ply fracture is detected. The number of iterations was extensively verified so that this criterion coincided with the unstable growth of a fibre break cluster.

Upon the detection of ply fracture, not all the fibres are already broken in the ply fracture location. Let us consider $z_{\min }$ and $z_{\max }$ to be the extreme axial locations of the unstable cluster of fibre breaks (see Figure 1), a failure index $I_{i, z}$ (see equation 8) can be determined for each unbroken fibre $i$ at a position $z$ between $z_{\min }$ and $z_{\max }$.

$I_{i, z}=\frac{\sigma_{i, z}}{\sigma_{i, z}^{\text {max }}}$

where $\sigma_{i, z}$ and $\sigma_{i, z}^{\max }$ are the longitudinal stress and strength, respectively, in the element at position $z$ of the fibre $i$. For yet unbroken fibres in the fracture region between $z_{\min }$ and $z_{\text {max }}$, the broken status is assigned to the fibre element with the maximum failure index. The ply fracture morphology is therefore approximated using the weakest elements between $z_{\min }$ and $z_{\max }$, resulting in an almost co-planar ply fracture. Although the ply fractures are almost co-planar, which is reasonable due to the explosive propagation of the critical cluster, they are not. The free morphology of the ply fracture is an extra source of variability in the model results. 


\section{Material parameters}

The results are presented in two phases: the validation of the model and a parametric study. The fibre properties used throughout the paper are the same for the both cases and are presented in Table 1. Changes in the fibre properties for the parametric study are indicated later in this article.

An epoxy matrix was modelled with a Young's modulus and Poisson's ratio of $3 \mathrm{GPa}$ and 0.4 , respectively. The plasticity law is given by equation 9 :

$\sigma_{p}=\sigma_{Y}\left(1+\frac{\varepsilon_{p}}{\alpha}\right)^{\beta}$

where $\sigma_{p}$ and $\varepsilon_{p}$ are the matrix plastic stress and plastic strain, respectively. $\sigma_{Y}, \alpha$ and $\beta$ were $46 \mathrm{MPa}, 0.0008 \mathrm{~mm} / \mathrm{mm}$ and 0.2 , respectively [20].

Three composites were designed for the study presented in this article. For the model validation, the composite was designed to replicate the experimental case. In this case, the stacking sequence was SG/C/SG, where SG stands for S-glass fibre/epoxy and C stands for TR30 carbon fibre/epoxy. For the model length optimisation and parametric study, an additional stacking sequence with dispersed carbon fibre plies

$\mathrm{SG} / \mathrm{C} / \mathrm{SG} / \mathrm{C} / \mathrm{SG} / \mathrm{C} / \mathrm{SG}$ was modelled. The fibre volume fraction in each ply was also increased by $10 \%$ in comparison with the validation case. The authors believe that this change in fibre volume fraction does not change the conclusions of the study performed. The ply properties for each case are detailed in Table 2 . All composites in the fibre break model were $1 \mathrm{~mm}$ in width.

A parametric study was performed using the model described in Section 2. The first parameter to be varied was the Weibull scale parameter, $\sigma_{0}$, of the S-glass fibres. $\sigma_{0}$ varied between 1 and $2.5 \mathrm{GPa}$ in steps of $0.5 \mathrm{GPa}$. The Weibull modulus values was varied from 5 to 7.5 and 10 . The $\sigma_{0}$ of the LE fibres was adjusted to obtain the same average failure strain $(1.65 \%)$ of the reference carbon fibre composite: 3029,3574 and $3927 \mathrm{MPa}$ for $m$ equal to 5, 7.5 and 10, respectively.

\section{Fragment length measurement}

The modelling results are compared to experimental results described in Czél et al. [31]. The fragment length was measured by the present authors on images of the postsaturation stage that were kindly provided by Gergely Czél (see Figure $4 \mathrm{~b}$ ). The images were enhanced to enable the visualisation of the ply fractures. The image on the righthand side (b) shows the crack paths used for the analysis of the fragment length. The fragment lengths were measured along the vertical blue line depicted in the image.

\section{Results and discussion}

\subsection{Dual-scale model length optimisation}

The stress-strain behaviour for stacking sequences with a single carbon ply and dispersed carbon plies is shown in Figure 5a. The stress-strain diagrams for the same stacking sequence overlap for all of the model lengths $(5,10,20$ and $40 \mathrm{~mm})$, showing that the ply fractures in the carbon plies occur between $1.9 \%$ and $2.2 \%$ of strain. The ply fractures occur when all the fibres are broken for a given location in the longitudinal 
direction. The higher number of fibre breaks, associated with the increase of $L_{r e c}$ for the case of a ply fracture, results sudden decrease in apparent stiffness and a consequent load drop in the stress-strain diagram. $L_{r e c}$ does not depend on the model length, so the magnitude of the stress drop decreases as the model length increases. This feature is highlighted in section A of Figure 5a, showing not only the different magnitude of the stress drops for each model length but also the frequency of the ply fractures. The longer models produce more ply fractures and therefore the frequency of the stress drops increases, thus maintaining the overall shape of the stress-strain diagram.

A noticeable difference observed with the increase in the model length is the reduction of the ultimate failure strain. Figure $5 \mathrm{~b}$ and $5 \mathrm{c}$ show a histogram of the failure strain as a function of the model length for each of the stacking sequences. The average failure strain decreases as the model length increases and it is lower for the dispersed carbon ply stacking sequence. The decrease can be explained by the weakest link theory, as more elements in the fibre direction increase the probability of a collection of nearby, relatively weak elements that cause early failure of the composite [32]. The final failure was observed to occur always in proximity of a carbon ply fracture, so the failure occurs due to the increased stress level in the S-glass plies potentiated by the carbon ply fracture. As the model length increases, there are more locations where the stress concentrations are applied and therefore it is more likely for the $\mathrm{S}$-glass plies to fracture for a lower failure strain. For $70 \%$ of the repetitions for the SG/C/SG/C/SG/C/SG stacking sequence, the ultimate failure initiated in one of the middle $\mathrm{S}$-glass plies. The higher stress concentrations applied by two adjacent carbon ply fractures make this event more likely and increase the probability of failure at a lower strain level.

The computational time required for each of the calculations depends on the dual-scale model's length. When the model length is changed from 20 to $40 \mathrm{~mm}$, the average failure strain decreased only $0.07 \%$ but the computational time of each repetition increased from 1.5 to 7.5 hours. The model length of $20 \mathrm{~mm}$ was chosen to be used in subsequent calculations.

\subsection{Ply fracture saturation and development of fibre break clusters}

When the density of carbon ply fractures is so high that a new ply fracture is very unlikely to happen, the fracture in the carbon plies is saturated. In this saturation state, the ply fragments exhibit a characteristic length which depends on the carbon ply thickness. This fact can be observed in Figure 6 as the fragment length for the both stacking sequences is within the same value range, even though the stacking sequences are different. The most likely fragment length to occur is $0.7 \pm 0.05 \mathrm{~mm}$ for both cases, which is about half of the maximum fragment length. The two values are related since the maximum fragment length is unlikely to be higher than the ply's ineffective length. If the distance between two ply fractures is higher than the ineffective length, it is likely that a new fracture occurs before the composite's final failure.

Finally, the model enables the analysis of the fibre break development throughout the failure development of the composite. The fibre breaks can be grouped in clusters of different sizes, as discussed in Section 2.3. Figure 7 shows the development of triplets, fibre break clusters made of 3 fibre breaks, as a function of the applied strain. A higher 
triplet density is observed in the dispersed carbon ply stacking sequence. The difference occurs due to the higher carbon fibre volume fraction in this stacking sequence. Both stacking sequences exhibit a peak in the triplet density at $1.9 \%$ of strain. Up to this strain level, most of the triplets are made of carbon fibre breaks but when the ply fractures start developing, the number of triplets reaches a peak. While ply fractures are developing, the triplets that were in proximity of a ply fracture tend to become part of the ply fracture. The development of the number of triplets reaches a balance between new triplets and the existing ones being converted into ply fractures. The number of triplets only increases again when more $S$-glass fibre breaks occur close to the ultimate failure.

\subsection{Model validation}

The present section compares 100 repetitions of the dual-scale model of SG/C/SG with experimental results [31] and an analytical model [9]. The parameters of the modelled and the experimentally studied materials correspond to the "Model validation" section in Table 2; the stacking sequence is SG/C/SG. Each repetition of the dual-scale model generates different fibre locations and fibre strength values. The analytical model [9] considers critical points in the failure of the composite to determine the stress-strain behaviour. The comparison is made on two aspects: the stress-strain behaviour of the composite and the ply fragment length distribution.

The stress-strain behaviour of the hybrid composite is depicted in Figure 8. The figure shows a representative prediction from the dual-scale model for the reference S-glass and the hybrid composite. A representative curve was chosen to demonstrate the dualscale model's predictions due to the low variability in the predictions $(0.2 \%$ in the highlighted region A in Figure 8) and to demonstrate the stress-drops due to the ply fractures. The same figure shows the experimental results and the analytical model predictions for the same hybrid stacking sequence.

The hybrid composite is predicted to undergo carbon ply fragmentation and saturation of ply fractures for the totality of the repetitions. According to Czél et al. [31], the carbon ply fractures occurred between $2.0 \%$ and $2.5 \%$ of strain, right before the knee in the experimental stress-strain diagram. The orange markers highlight the ply fracture points in the dual-scale model, occurring between 1.7 and $2.5 \%$ of strain. Therefore, the ply fractures in the dual-scale model start occurring at a lower strain compared to the experiments. The plateau in the stress-strain diagram of the analytical model occurs for lower stress levels. The same is valid for the final failure of the composite, where the predicted failure strain $(5.1 \pm 0.2 \%)$ is well above the experimental results $(3.8 \pm 0.2 \%)$. This deviation is explained by the approximate nature of the used Weibull distribution for the carbon and glass fibres strength. The Weibull strength distribution for these particular fibres was not available and a decision was made not to fit the experimental data. More work should be done in measuring the Weibull strength distribution of the fibres and scaling the distribution to the short gauge lengths used for the fibre elements [33].

The disparity between the post-saturation stiffness in the experiments and the dual-scale model, seen in the diagrams shown in Figure 8, may have two sources: interlaminar delamination and non-linear behaviour of the S-glass plies in the experiments. The 
model predicts a post-saturation stiffness of $43.2 \pm 0.7 \mathrm{GPa}$. In the current formulation the model does not capture delamination but in the case of complete delamination of the carbon ply, the stiffness of the hybrid composite, would have been $40.7 \mathrm{GPa}$. The experiments show a post-saturation stiffness of $33.3 \pm 0.8 \mathrm{GPa}$, which can only be explained by softening of the $\mathrm{S}$-glass plies. The non-linear behaviour of glass fibres has not been explicitly reported in literature to the best of our knowledge. However, through careful analysis of the experimental stress-strain diagrams in the literature [34,35], it is possible to conclude that UD glass composites exhibit a non-linear behaviour. Other effects such as the accumulation of fibre breaks [22] and consequent fibre debonding in the $\mathrm{S}$-glass plies can also contribute to the stiffness degradation of the composite. It seems unrealistic though that such mechanisms would cause the significant stiffness degradation measured in the experiments.

The stiffness degradation predicted by the dual-scale model does agree with the analytical model predictions. The post-saturation stiffness is predicted to be $43.9 \mathrm{GPa}$. The main difference between the two models is the level of the fragmentation stress. While the analytical model assumes a plateau at the fragmentation stress, the dual-scale model takes into account the fibre break statistics and captures the variability in the carbon ply strength and the hybrid effect. Figure 8 illustrates the predictions of the ply fracture strain by the dual-scale model: it is $1.7-2.5 \%$, close to the experimental observations of $2-2.5 \%$, whilst the analytical model gives $1.6-1.8 \%$, which is off the experimental values.

The second comparative aspect, the distance between consecutive ply fractures or fragment length, is shown in Figure 4a. The average fragment length predicted by the dual-scale model underestimates the experimental observations. It is possible that short delamination occurred around the ply fractures. An average delamination length of $130 \mu \mathrm{m}$ would increase the distance between ply fractures and explain the difference. The original purpose of the experimental videos was not to analyse the ply fracture distances, so the image quality was not optimal for the analysis. A deviation of 1 pixel $(1$ pixel $=170 \mu \mathrm{m})$ in the image analysis would also cause the difference in the average fragment length.

\subsection{Parametric study}

The versatility of the dual-scale model allows the user to tailor the material properties and to study several material systems and stacking sequences. While the analytical model is limited to hybrid composites with a single LE ply, the new dual-scale model is able to predict the behaviour of hybrids with multiple LE plies. This added degree of freedom in the design of composites is of immense value as fibre hybrids with dispersed LE plies show a pseudo-ductile behaviour for higher LE fibre contents [36].

In this section, the results from the parametric study described in Section 3 is analysed. The number of repetitions of the model for each case was 100.

\subsubsection{HE fibre Weibull scale parameter}

The properties of the HE fibres can determine the failure mechanism of a given stacking sequence. For example, if the HE fibres have a low Weibull scale parameter, the first LE ply fracture will trigger the ultimate failure of the composite immediately. By 
contrast, if the Weibull scale parameter is high enough, the LE ply can fracture multiple times, reaching the saturation state. The failure of the HE plies will only be triggered when the combined effect of applied strain and the stress concentrations from the LE ply fracture is sufficiently pronounced. In between, if the HE fibres' Weibull scale parameter is not too low or too high, the LE plies are able to fracture multiple times before the composite fails but the LE plies do not saturate with fractures. This section analyses the variation of the failure mechanism as a function of the HE fibre Weibull scale parameter.

Figure 9 shows the failure mechanism variation as the S-glass fibre Weibull scale parameter $\sigma_{0}$ is gradually varied from $1 \mathrm{GPa}$ to $2.5 \mathrm{GPa}$. Each bar corresponds to 100 repetitions of the model for the same fibre properties. As $\sigma_{0}$ increases, the failure mechanism transitions from immediate failure of the S-glass plies to the carbon ply fracture saturation in most of the repetitions. The denominated "Partial saturation" stands for the case when at least one of the carbon plies in the composite reaches a saturation state but not all of them do. The stacking sequence with a single carbon ply is more prone to fail with a saturated carbon ply as the transition between failure mechanisms occurs for a lower $\sigma_{0}$. The Weibull scale parameter of the HE fibres can directly affect the ply fragmentation behaviour in the LE plies.

As an additional model insight, the results of this model were compared to the predictions of equation 10, presented in the work of Czél et al. [31]:

$\sigma_{H E}>\frac{\sigma_{L E} \cdot\left(2 \cdot E_{H E} \cdot t_{H E}+E_{L E} \cdot t_{L E}\right)}{2 \cdot E_{L E} \cdot t_{H E}}$

where $\sigma$ is the ply strength, $E$ is the ply stiffness and $t$ is the ply thickness and the subscripts $H E$ and $L E$ refer to the high elongation and low elongation material, respectively. Through equation 10 , it can be concluded that the minimum ply strength of the HE material to withstand the first LE ply fracture and not to fail immediately is $1480 \mathrm{MPa}$. Figure 9 shows that the hybrid composites transition from immediate fracture to multiple fractures when $\sigma_{0}$ is varied between 1 and $1.5 \mathrm{GPa}$. According to the model, the S-glass/epoxy composite strength is $1118.9 \pm 2.5 \mathrm{MPa}$ and $1679.0 \pm$ 5.6 $\mathrm{MPa}$ for $\sigma_{0}$ equal to $1 \mathrm{GPa}$ and $1.5 \mathrm{GPa}$, respectively. Taking into account these predictions, it can be concluded that equation 10 is a simple way of pre-designing the hybrid composite if a ply fragmentation failure mode is desired. Figure 9, however, shows that for a single Weibull scale parameter of the HE plies, multiple failure modes are possible. The failure mode therefore depends on the intrinsic material variability. This is a key benefit of the present modelling approach over equation 10.

\subsubsection{LE fibre Weibull modulus}

Different LE fibres may have different Weibull moduli but still produce composites with similar failure strain. That effect is explored in this section, with the carbon fibre Weibull modulus, $m$, taking values of 5, 7.5 and 10. Even though the average failure strain of the reference material is the same, the Weibull modulus variation produces significant differences in the hybrid composite's stress-strain diagram.

Figure 10 proves that the stress in the composite with a Weibull modulus of 10 only slightly increases during the fragmentation process. A lower LE fibre Weibull modulus is translated into a higher variability in the carbon ply strength and therefore higher 
stress variations are required between ply fractures. The strain interval where ply fractures occur also increases with the decrease in the Weibull modulus. For the carbon fibres with a lower Weibull modulus, the last carbon ply fracture occurs for a higher strain. The effect of the carbon fibre Weibull modulus variation is similar in both stacking sequences. An LE fibre type with a lower Weibull modulus is preferable to obtain a more gradual failure of the hybrid composite.

Varying the Weibull modulus also changes the fibre break triplet evolution, as can be observed in Figure 11. A lower Weibull modulus enables a higher triplet density without fracturing a ply. The higher strength scatter delays the ply fractures as a critical defect is not able to propagate anymore due to the very strong fibre elements in its vicinity. The triplets therefore accumulate to a higher density before the ply fractures start occurring. The peak in the triplet density seems to occur at the same strain level for all cases. Taking into account the results shown in Figure 7, the ply fractures start occurring at the same strain level.

\section{Conclusions}

A modelling approach was proposed to predict the behaviour of UD interply fibre hybrid composites under tensile load up to their failure. The model combines phenomena at two scales: fibre breaks at the micro-level and ply fractures at the mesolevel. It uses as input properties of the two fiber types and the matrix and predicts the stress-strain behaviour the composite. The behaviour of a hybrid composite with any number of thin LE plies can be modelled.

The model's predictions were compared with experimental results for the carbon/glass composite and revealed good agreement between key features in the behaviour and failure mode. A non-linearity in the stress-strain diagram during the ply fragmentation process was obtained and the fragment length in the saturated state is similar to the experimental results. The ultimate failure strain deviates from the experimental results likely due to the approximate nature of the Weibull strength parameters for the fibres used in the model. Further work on the measurement of single fibre properties and the scaling of the Weibull strength distribution to very short gauge lengths is necessary.

The parametric study revealed that the failure behaviour should be modelled with a model length of $20 \mathrm{~mm}$ for accuracy and computational speed. The ultimate failure strain of the composite shows a decreasing trend as the model length increases, but the relative variation is less than $1.4 \%$ between 20 and $40 \mathrm{~mm}$. Changing the Weibull scale parameter of the HE fibres showed that the failure mode of the composite can be changed by choosing a different HE fibre type. A HE fibre with a high Weibull scale parameter is necessary to achieve saturation of LE ply fractures. The LE fibre Weibull modulus has a strong influence on the ply fragmentation development. A fibre with a lower Weibull modulus should be used if a more gradual failure development is wanted.

The fibre break development can be used to describe the meso-level phenomena in interply fibre hybrids. The higher versatility of this model allows the prediction of the tensile behaviour of UD hybrid composites with complex microstructures. 


\section{Acknowledgments}

The research leading to these results has been done within the framework of the FiBreMoD project and has received funding from the European Union's Horizon 2020 research and innovation programme under the Marie Skłodowska-Curie grant agreement No 722626. YS acknowledges FWO Flanders for his postdoctoral fellowship. SL holds Toray Chair for Composite Materials, the support of which is acknowledged.

\section{References}

[1] Y. Swolfs, L. Gorbatikh, I. Verpoest, Fibre hybridisation in polymer composites: A review, Compos. Part A Appl. Sci. Manuf. 67 (2014) 181-200.

[2] G. Czél, M. Jalalvand, M.R. Wisnom, Demonstration of pseudo-ductility in unidirectional hybrid composites made of discontinuous carbon/epoxy and continuous glass/epoxy plies, Compos. Part A Appl. Sci. Manuf. 72 (2015) 7584.

[3] R.P. Tavares, A.R. Melro, M.A. Bessa, A. Turon, W.K. Liu, P.P. Camanho, Mechanics of hybrid polymer composites: analytical and computational study, Comput. Mech. 57 (2016) 405-421.

[4] J.M. Guerrero, J.A. Mayugo, J. Costa, A. Turon, A 3D Progressive Failure Model for predicting pseudo-ductility in hybrid unidirectional composite materials under fibre tensile loading, Compos. Part A Appl. Sci. Manuf. 107 (2018) 579-591.

[5] S. Pimenta, P. Robinson, Modelling the tensile response of unidirectional hybrid composites, 16th Eur. Conf. Compos. Mater. ECCM 2014. (2014) 22-26.

[6] Y. Swolfs, I. Verpoest, L. Gorbatikh, Maximising the hybrid effect in unidirectional hybrid composites, Mater. Des. 93 (2016) 39-45.

[7] G. Dai, L. Mishnaevsky, Fatigue of hybrid glass/carbon composites: 3D computational studies, Compos. Sci. Technol. 94 (2014) 71-79.

[8] A.F.A. Ghani, Y. Yaakob, R. Jumaidin, M.B. Ali, M.A. Shaharuzaman, S. Dharmalingam, Finite Element Modeling Failure Prediction of Hybrid Composite CFRP / GFRP, J. Telecomunication, Electron. Comput. Eng. 10 (2018) 131-135.

[9] M. Jalalvand, G. Czél, M.R. Wisnom, Damage analysis of pseudo-ductile thinply UD hybrid composites - A new analytical method, Compos. Part A Appl. Sci. Manuf. 69 (2015) 83-93.

[10] D.K. Patel, A.M. Waas, Damage and failure modelling of hybrid threedimensional textile composites: A mesh objective multi-scale approach, Philos. Trans. R. Soc. A Math. Phys. Eng. Sci. 374 (2016).

[11] M. Jalalvand, G. Czél, M.R. Wisnom, Numerical modelling of the damage modes in UD thin carbon/glass hybrid laminates, Compos. Sci. Technol. 94 (2014) 3947.

[12] Y. Swolfs, I. Verpoest, L. Gorbatikh, Recent advances in fibre-hybrid composites: materials selection, opportunities and applications, Int. Mater. Rev. 64 (2019) 181-215.

[13] A.R. Melro, P.P. Camanho, S.T. Pinho, Generation of random distribution of fibres in long-fibre reinforced composites, Compos. Sci. Technol. 68 (2008) 2092-2102.

[14] V. Romanov, S. V. Lomov, Y. Swolfs, S. Orlova, L. Gorbatikh, I. Verpoest, 
Statistical analysis of real and simulated fibre arrangements in unidirectional composites, Compos. Sci. Technol. 87 (2013) 126-134.

[15] Y. Swolfs, L. Gorbatikh, I. Verpoest, Stress concentrations in hybrid unidirectional fibre-reinforced composites with random fibre packings, Compos. Sci. Technol. 85 (2013) 10-16.

[16] B.J. Gellatly, J.L. Finney, Characterisation of models of multicomponent amorphous metals: The radical alternative to the Voronoi polyhedron, J. Non. Cryst. Solids. 50 (1982) 313-329.

[17] G. Czél, M.R. Wisnom, Demonstration of pseudo-ductility in high performance glass/epoxy composites by hybridisation with thin-ply carbon prepreg, Compos. Part A Appl. Sci. Manuf. 52 (2013) 23-30.

[18] Y. Swolfs, L. Gorbatikh, V. Romanov, S. Orlova, S. V. Lomov, I. Verpoest, Stress concentrations in an impregnated fibre bundle with random fibre packing, Compos. Sci. Technol. 74 (2013) 113-120.

[19] Y. Swolfs, R.M. McMeeking, I. Verpoest, L. Gorbatikh, Matrix cracks around fibre breaks and their effect on stress redistribution and failure development in unidirectional composites, Compos. Sci. Technol. 108 (2015) 16-22.

[20] T. Okabe, K. Ishii, M. Nishikawa, N. Takeda, Prediction of Tensile Strength of Unidirectional CFRP Composites, J. Japan Soc. Compos. Mater. 33 (2007) 205212.

[21] Y. Swolfs, H. Morton, A.E. Scott, L. Gorbatikh, P.A.S. Reed, I. Sinclair, S.M. Spearing, I. Verpoest, Synchrotron radiation computed tomography for experimental validation of a tensile strength model for unidirectional fibrereinforced composites, Compos. Part A Appl. Sci. Manuf. 77 (2015) 106-113.

[22] A. Bunsell, L. Gorbatikh, H. Morton, S. Pimenta, I. Sinclair, M. Spearing, Y. Swolfs, A. Thionnet, Benchmarking of strength models for unidirectional composites under longitudinal tension, Compos. Part A Appl. Sci. Manuf. 111 (2018) 138-150.

[23] Y. Swolfs, R.M. McMeeking, I. Verpoest, L. Gorbatikh, The effect of fibre dispersion on initial failure strain and cluster development in unidirectional carbon/glass hybrid composites, Compos. Part A Appl. Sci. Manuf. 69 (2014) 279-287.

[24] B.W. Rosen, Tensile failure of fibrous composites, AIAA J. 2 (1964) 1985-1991.

[25] J. Watanabe, F. Tanaka, H. Okuda, T. Okabe, Tensile strength distribution of carbon fibers at short gauge lengths, Adv. Compos. Mater. 23 (2014) 535-550.

[26] H. Okuda, R.J. Young, F. Tanaka, J. Watanabe, T. Okabe, Tensile failure phenomena in carbon fibres, Carbon N. Y. 107 (2016) 474-481.

[27] C.P. Beetz Jr, The analysis of carbon fibre strength distributions exhibiting multiple modes of failure, Fibre Sci. Technol. 16 (1982) 45-59.

[28] F.W. Zok, On weakest link theory and Weibull statistics, J. Am. Ceram. Soc. 100 (2017) 1265-1268.

[29] T. Jung, R. V Subramanian, V.S. Manoranjan, Prediction of fibre strength at the critical length: a simulation theory and experimental verification for bimodally distributed carbon fibre strengths, J. Mater. Sci. 28 (1993) 4489-4496.

[30] K. Goda, H. Fukunaga, The evaluation of the strength distribution of silicon carbide and alumina fibres by a multi-modal Weibull distribution, J. Mater. Sci. 
21 (1986) 4475-4480.

[31] G. Czél, M. Jalalvand, M.R. Wisnom, Design and characterisation of advanced pseudo-ductile unidirectional thin-ply carbon/epoxy-glass/epoxy hybrid composites, Compos. Struct. 143 (2016) 362-370.

[32] W. Weibull, A statistical distribution function of wide applicability, J. Appl. Mech. 103 (1951) 293-297.

[33] Y. Swolfs, I. Verpoest, L. Gorbatikh, A review of input data and modelling assumptions in longitudinal strength models for unidirectional fibre-reinforced composites, Compos. Struct. 150 (2016) 153-172.

[34] I.M. Daniel, T. Liber, Lamination residual stresses in fiber composites, NASA Interim Report CR-134826, 1975.

[35] B. Khan, K. Potter, S.R. Hallett, M.R. Wisnom, Size effects in unidirectional and quasi-isotropic composites loaded in tension, in: 2nd Int. Conf. Compos. Test. Model Identif., 2004: pp. 30-31.

[36] M. Selezneva, Y. Swolfs, A. Katalagarianakis, T. Ichikawa, N. Hirano, I. Taketa, T. Karaki, I. Verpoest, L. Gorbatikh, The brittle-to-ductile transition in tensile and impact behavior of hybrid carbon fibre/self-reinforced polypropylene composites, Compos. Part A Appl. Sci. Manuf. 109 (2018) 20-30.

[37] M.R. Wisnom, G. Czél, Y. Swolfs, M. Jalalvand, L. Gorbatikh, I. Verpoest, Hybrid effects in thin ply carbon/glass unidirectional laminates: Accurate experimental determination and prediction, Compos. Part A Appl. Sci. Manuf. 88 (2016) 131-139.

[38] D. Hartman, M.E. Greenwood, D.M. Miller, High strength glass fibers, Owens Corning, Inc., Tech. Pap. Ref. 1-PI-19025-A, July 1996. Repr. by AGY LLC as Pub No. LIT-2001-011 (05/01), May 2001. (n.d.).

[39] R. Ganesh, S. Sockalingam, B.Z. (Gama) Haque, J.W. Gillespie, Dynamic effects of single fiber break in unidirectional glass fiber-reinforced composites, J.

Compos. Mater. 51 (2017) 1307-1320. 


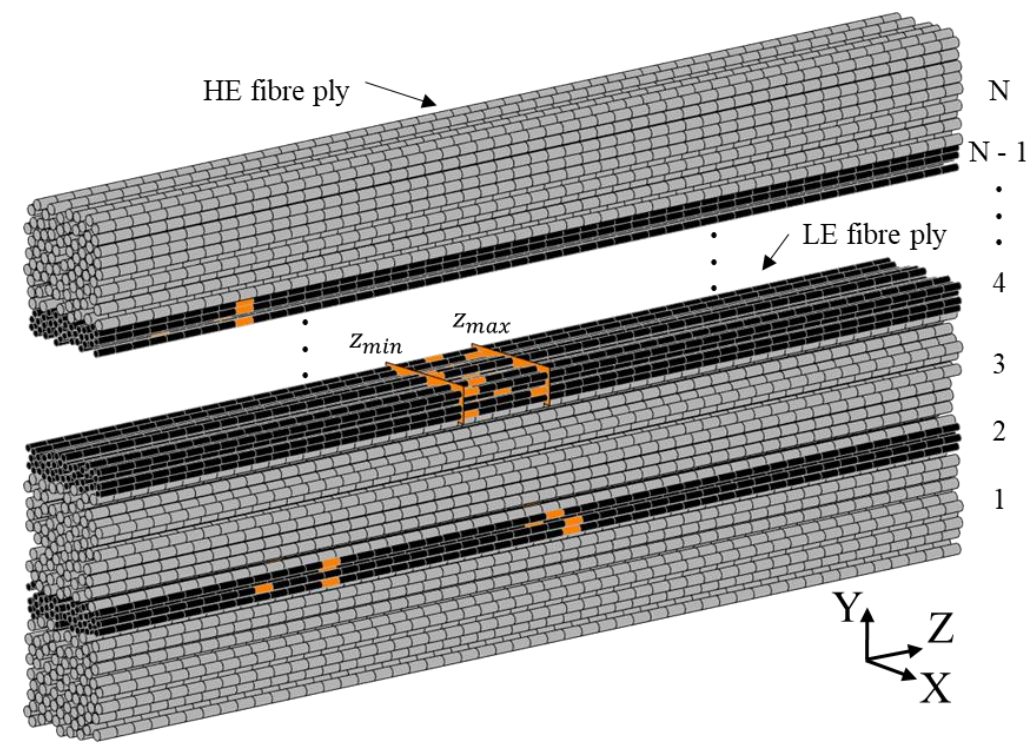

Figure 1 - Interply fibre-hybrid composite with $\mathrm{N}$ alternating LE and HE plies and random fibre packing. The fibre breaks that gave way to the ply fractures are highlighted. In the ply $n^{\circ}$, the ply fracture occurred between $z_{\min }$ and $z_{\text {max }}$.

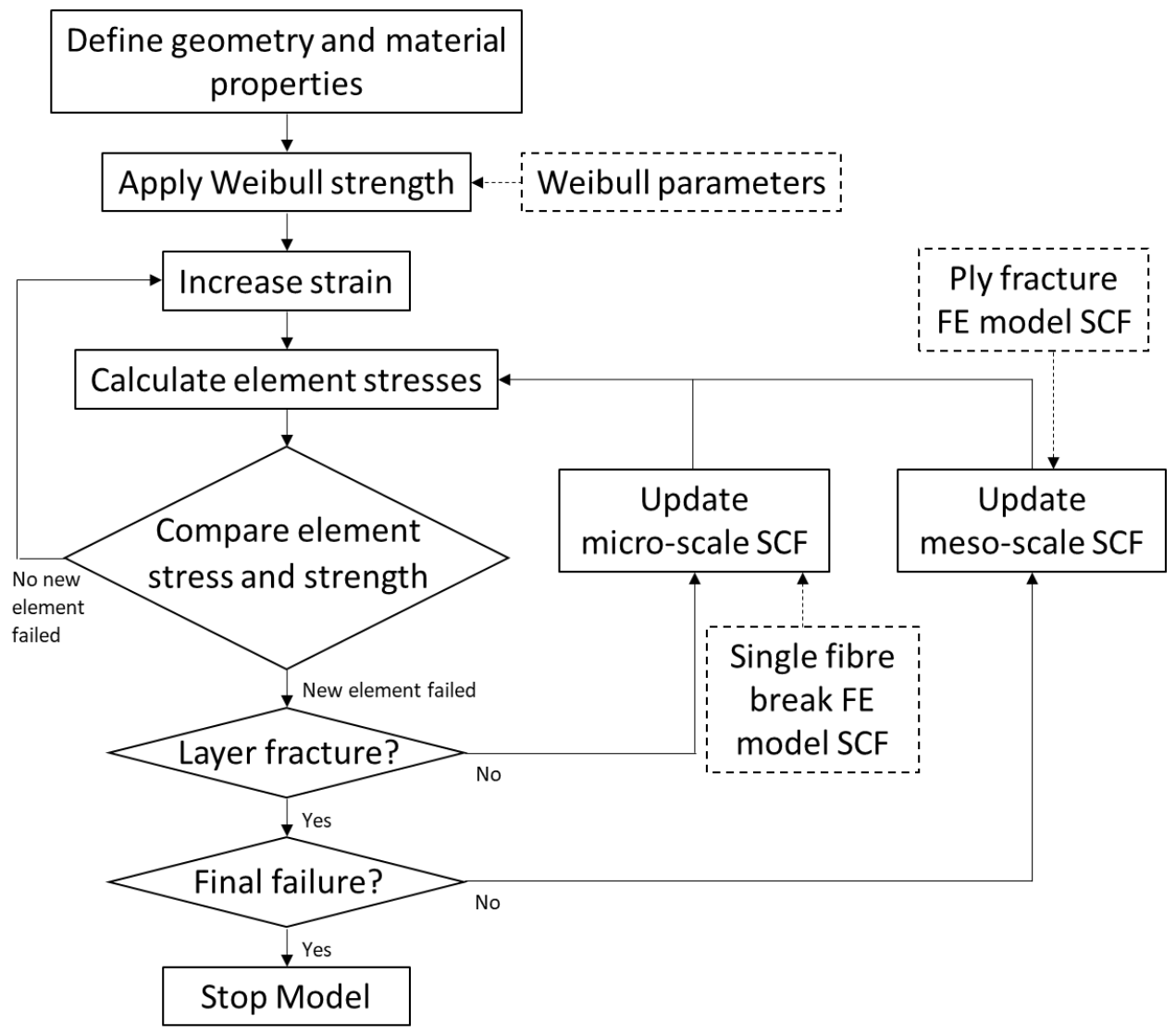

Figure 2 - Flow chart of the dual-scale model. The SCF input origins from FE models and differs between the micro-scale fibre breaks and the meso-scale ply fractures. 


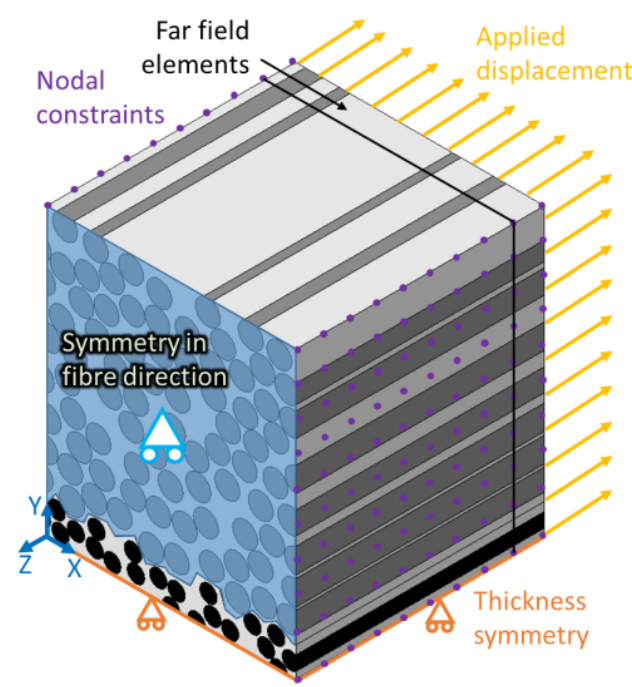

(a)

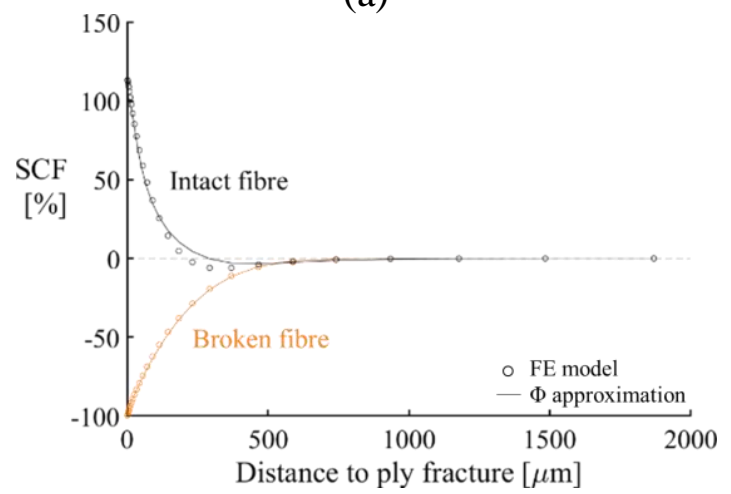

(c)

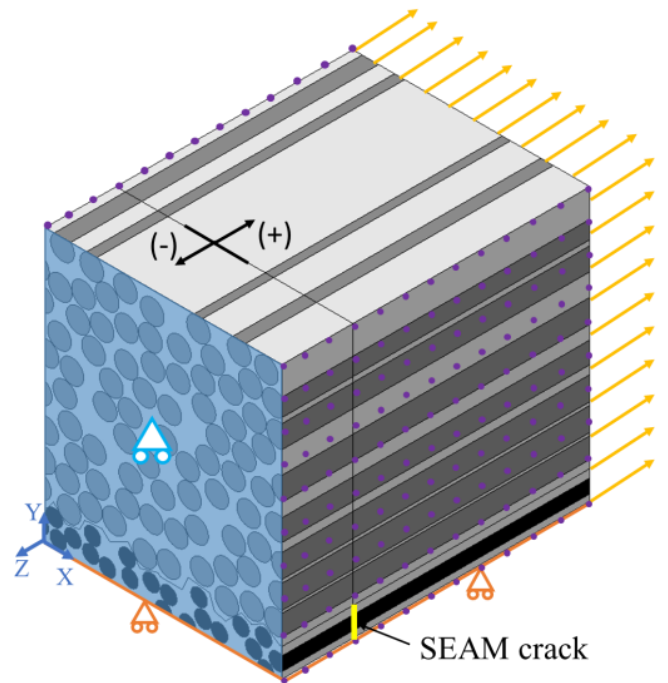

(b)

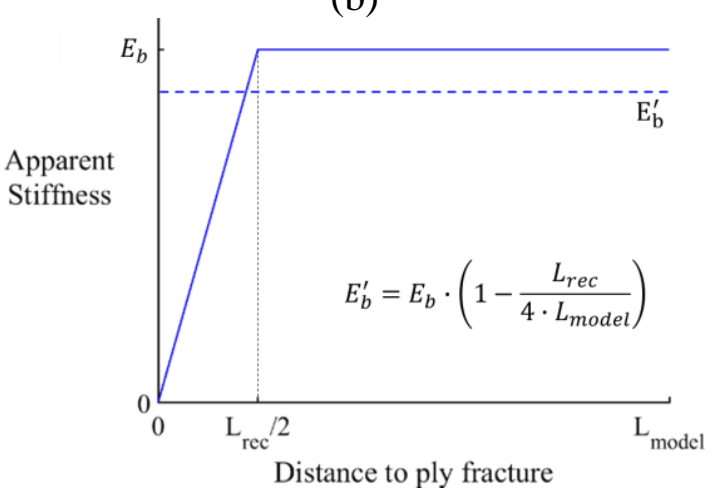

(d)

Figure 3 - FE model depicting a single ply fracture (a) and two ply fractures (b). For visualisation purposes, the fibre length was made shorter in the figure than the version used for the simulations. The (+) and (-) side of the ply fractures in (b) are explained in the text. The stress concentrations extracted from the FE model and corresponding approximation function $\Phi$ are represented in (c) and the variation in the broken fibre's apparent stiffness is depicted in (d). 

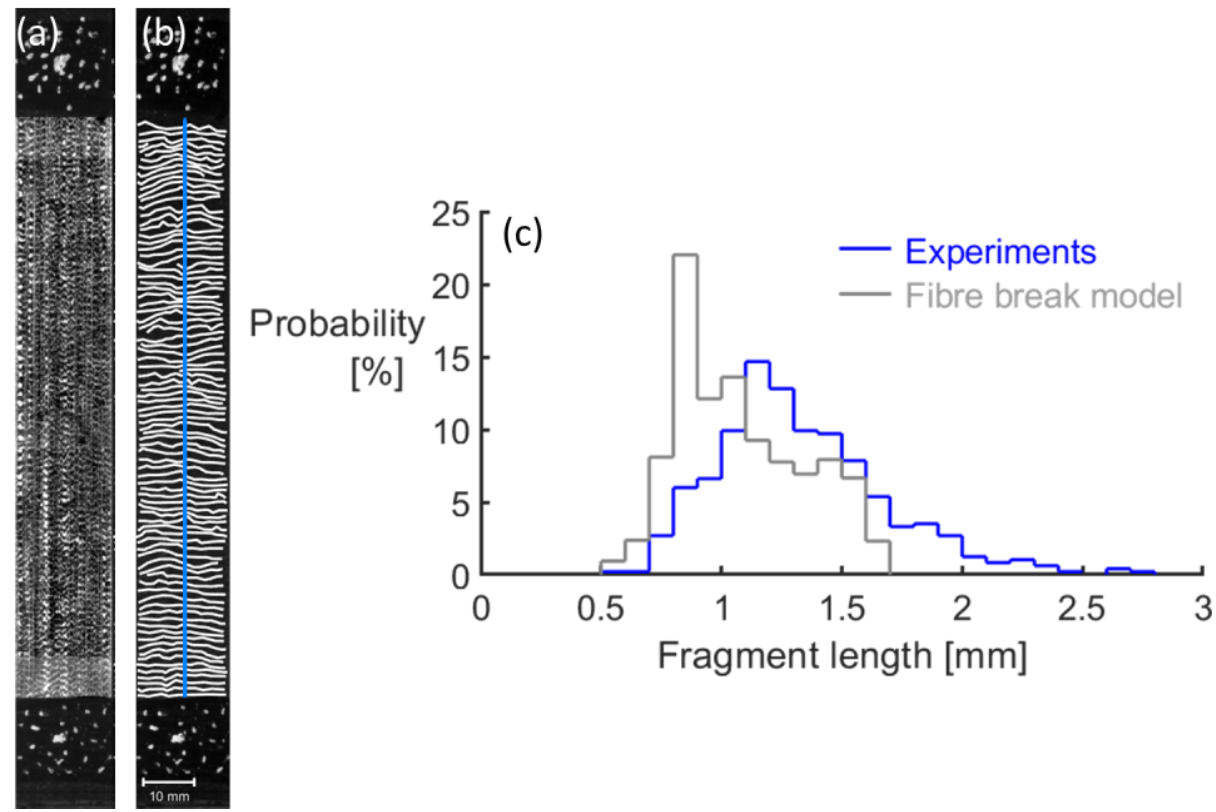

Figure 4 - Ply fragment length analysis: (a) analysed sample image, (b) the ply fracture paths measured in the experiments along the blue line and (c) distance between consecutive ply fractures compared between the dual-scale model predictions and the experimental results.
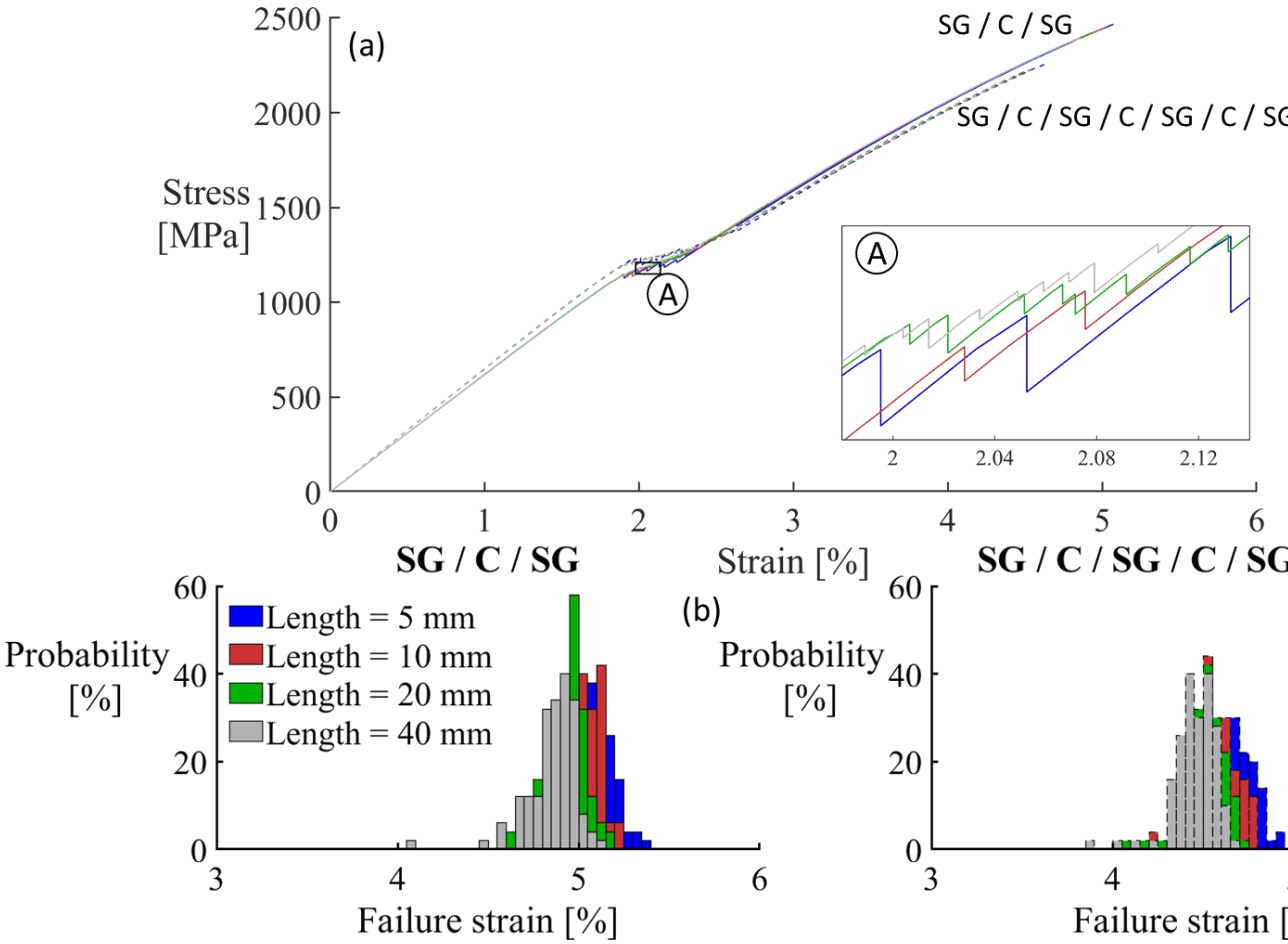

(b)
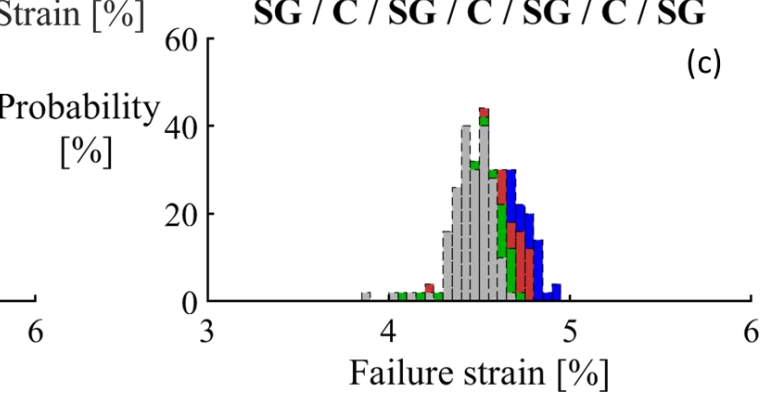

Figure 5 - Stress-strain diagrams predicted by the model for different model lengths (a) and the ultimate failure strain as a function of the model length for each of the stacking sequences (b) and (c). Section A shows the difference in the load drop magnitude and frequency for each model length. 


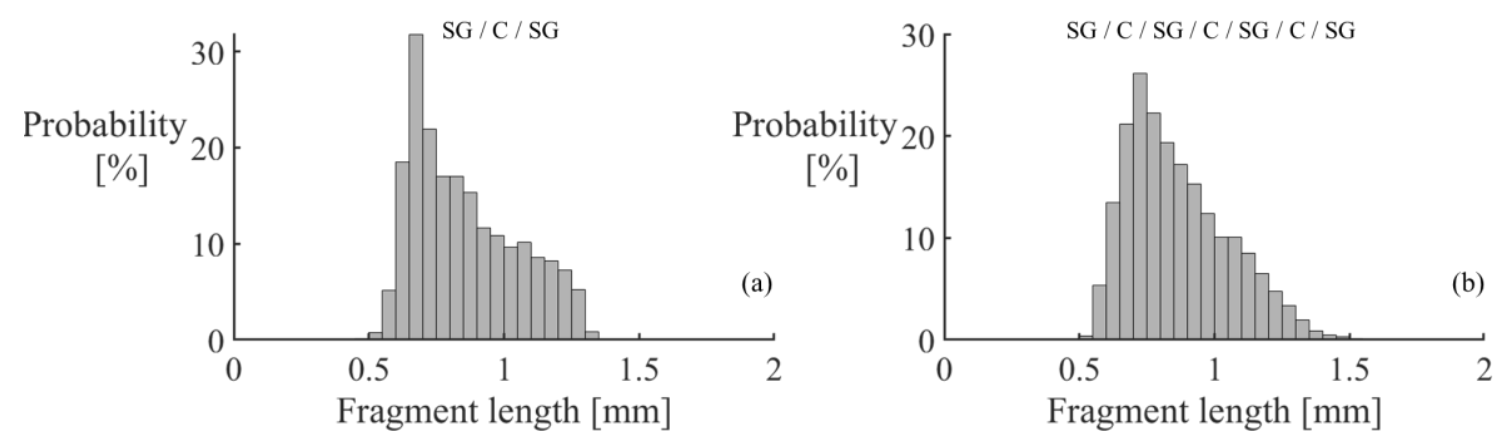

Figure 6 -Fragment length in the carbon plies in the post-saturation state for the single carbon ply (a) and dispersed carbon plies (b) stacking sequence. The data shown was obtained for the models with $20 \mathrm{~mm}$ fibre length.

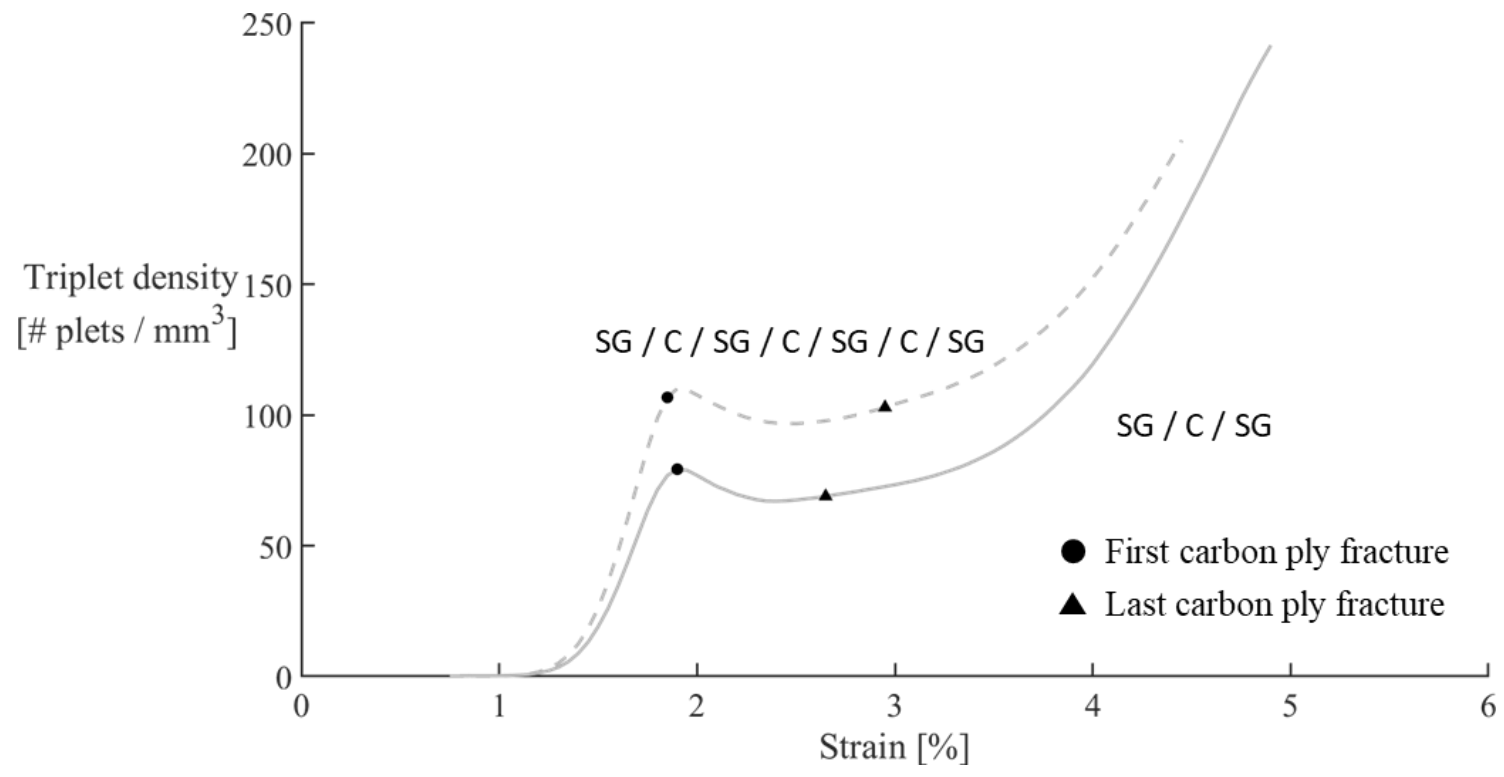

Figure 7 - Evolution of the triplet density as the failure in the composite develops. The average strain of the first and last carbon ply fractures are depicted with a circle and triangle, respectively. 


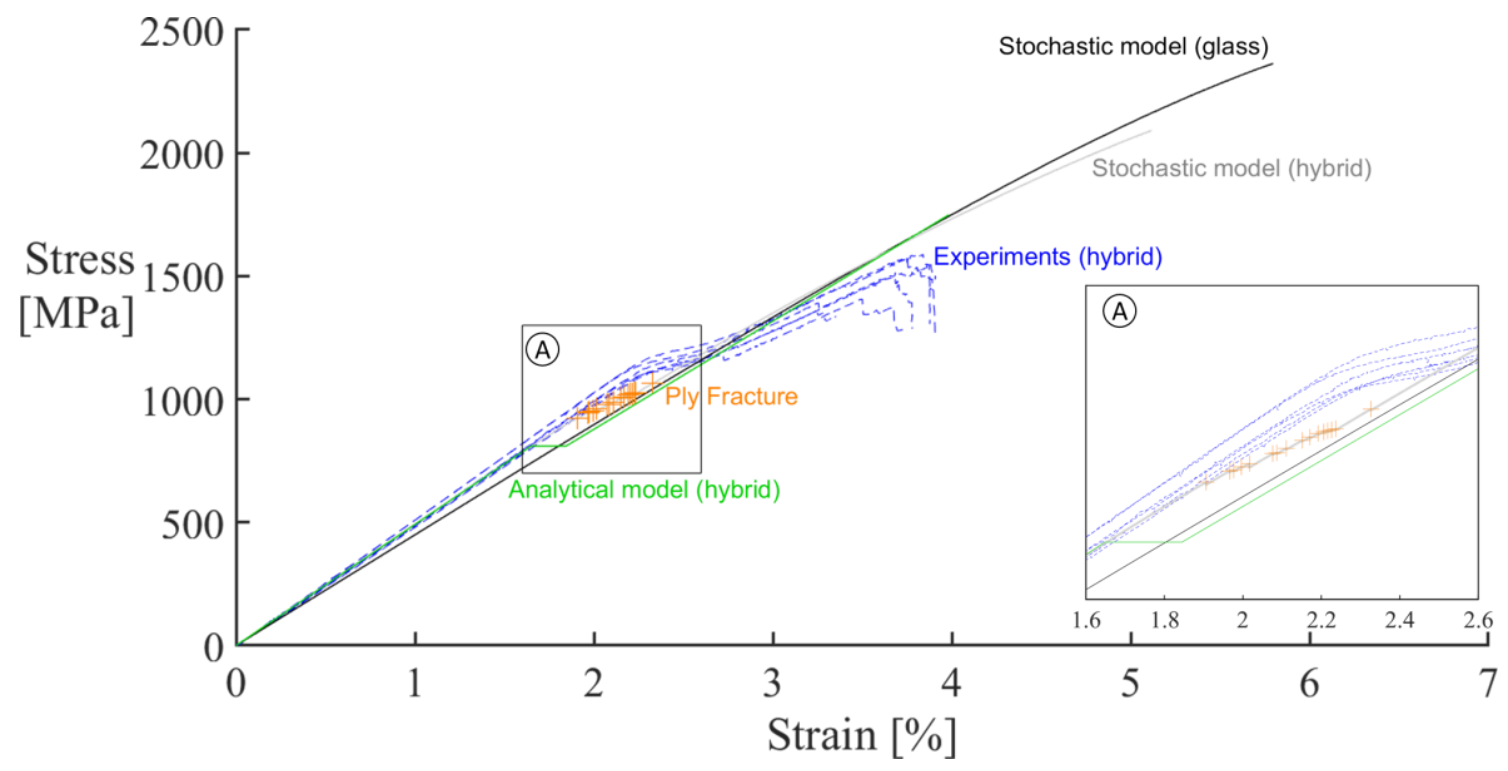

Figure 8 - Representative stress-strain behaviour predicted by the dual-scale model for the S-glass reference composite and the hybrid SG/C/SG composite overlapped with the experimental results and the analytical model predictions. The ply fracture stresses and strains predicted by the dual-scale model are depicted with (+) orange markers. Section A shows the interval where ply fractures occur. The confidence intervals in section $A$ are within $0.2 \%$ of the representative curve.

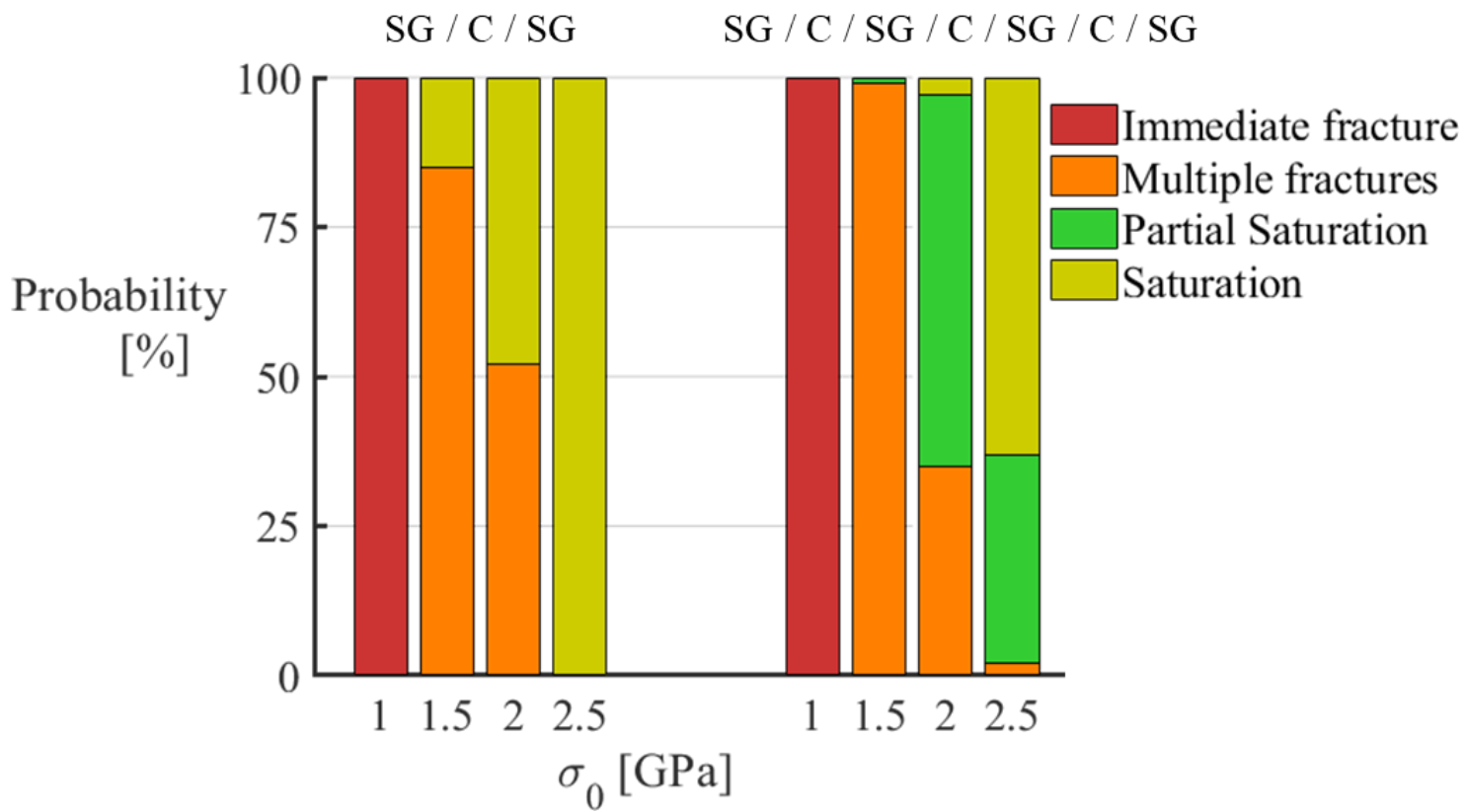

Figure 9 - Failure mode transition from immediate fracture of the composite to a saturation state as the Weibull scale parameter of the $S$-glass fibres increases. The SG/C/SG stacking sequence is more prone to achieving a saturated carbon ply. 

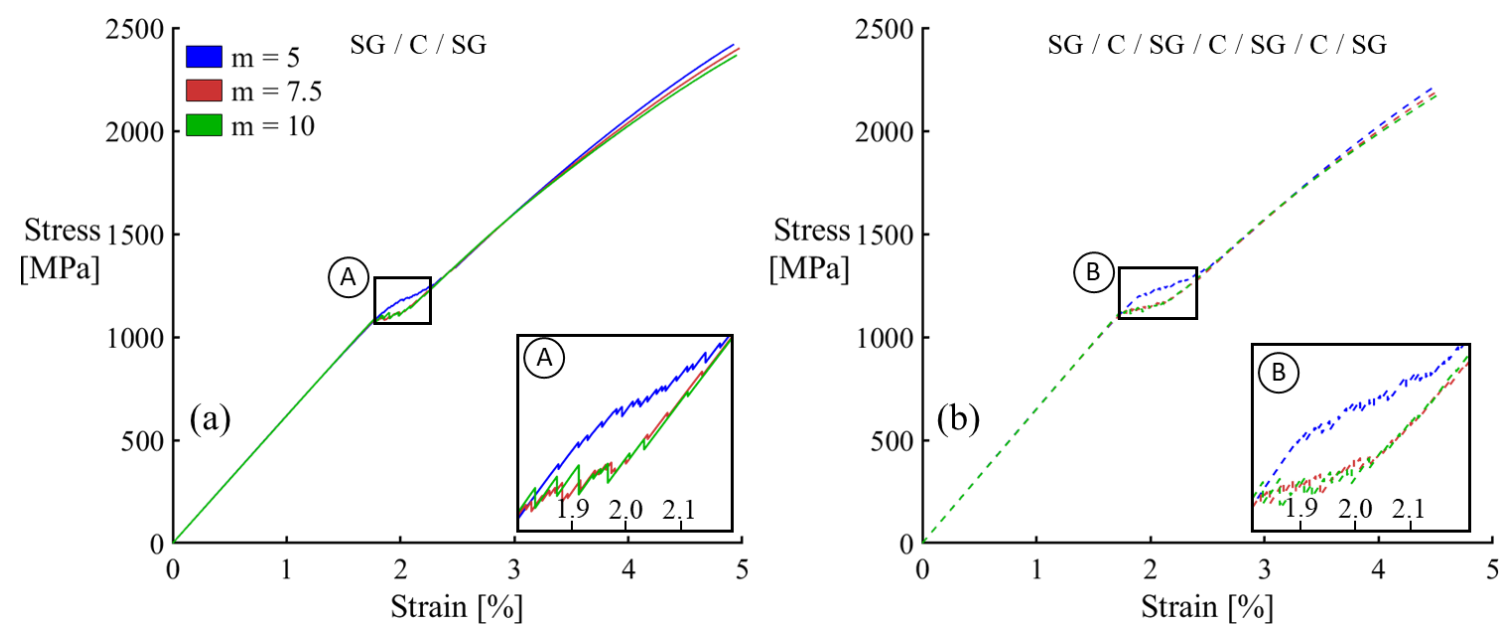

Figure 10 - Stress-strain behaviour of the (a) single carbon ply and (b) dispersed carbon plies stacking sequences as a function of the carbon fibre Weibull modulus. The non-linearity during the ply fragmentation is more pronounced as the Weibull modulus increases.
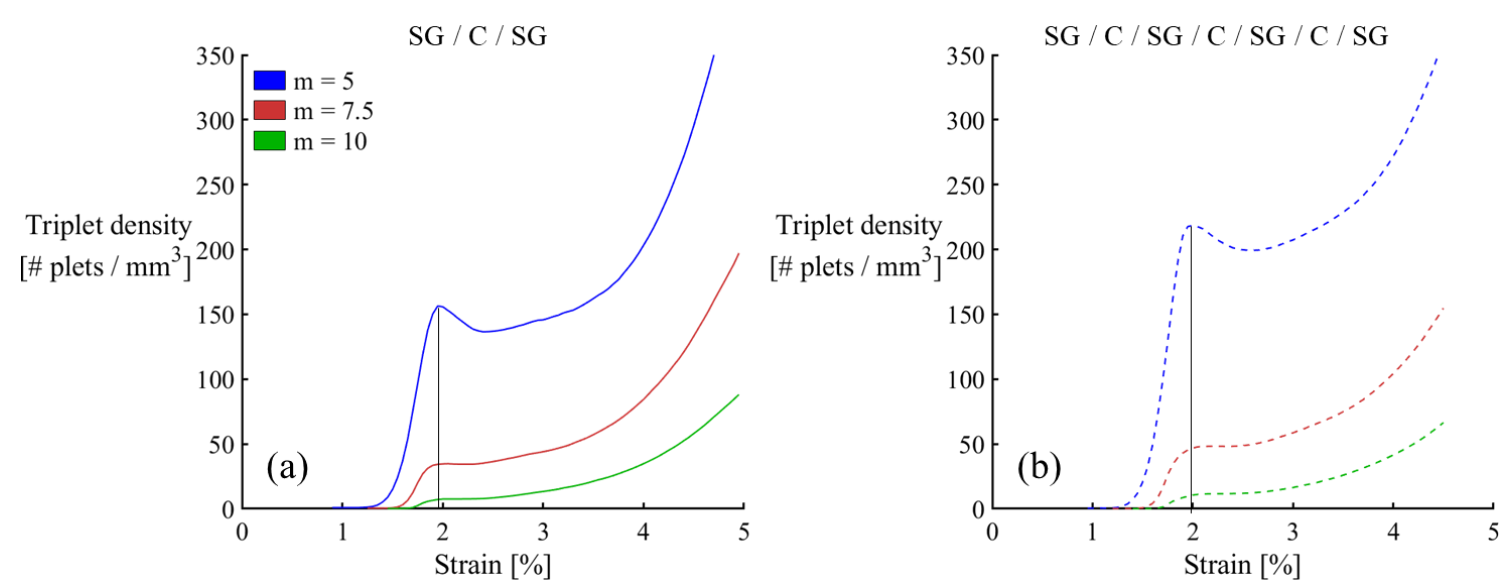

Figure 11 - Evolution of the fibre break triplets for the (a) single carbon ply and

(b) dispersed carbon plies stacking sequences as a function of the carbon fibre Weibull modulus. The peak in the triplet density occurs at a slightly higher strain level as the Weibull modulus increases. 
Table 1 - Properties of the fibres used in the model.

\begin{tabular}{ccc} 
Fibre property & $\begin{array}{c}\text { TR30 carbon fibre } \\
{[37]}\end{array}$ & $\begin{array}{c}\text { S-glass fibre } \\
{[38,39]}\end{array}$ \\
\hline Fibre diameter $[\mu \mathrm{m}]$ & 7 & 10 \\
Longitudinal elastic modulus [GPa] & 230 & 86.9 \\
Transverse elastic modulus [GPa] & 15 & 86.9 \\
Poisson's ratio, LT & 0.25 & 0.22 \\
Weibull scale parameter [MPa] & 3029 & 2645 \\
Weibull modulus [-] & 5 & 4.52 \\
Reference gauge length [mm] & 10 & 25.4
\end{tabular}

Table 2 - Laminate properties used in the model.

\begin{tabular}{ccc} 
Laminate property & $\begin{array}{c}\text { TR30 carbon } \\
\text { fibre / epoxy }\end{array}$ & $\begin{array}{c}\text { S-glass fibre / } \\
\text { epoxy }\end{array}$ \\
\hline \multicolumn{2}{c}{ Model Validation } \\
Ply thickness $[\mu \mathrm{m}]$ & 29 & 155 \\
Ply fibre volume fraction $[\%]$ & 40 & 50 \\
\hline
\end{tabular}

Parametric Study \& Model length optimisation
Ply thickness $[\mu \mathrm{m}]$
30
100

Ply fibre volume fraction [\%]

50

60 